\section{Alpha E beta 7}

P J Kilshaw

\begin{abstract}
$\alpha \mathrm{E} \beta 7$ is a member of the integrin family and is expressed almost exclusively by cells of the $T$ lymphocyte lineage in mucosal tissues. Expression is induced by transforming growth factor $\beta$ in the mucosal microenvironment. Genetic elements that control transcription are under investigation and may prove valuable for directing the expression of transgenes in mucosal $T$ cells. The only known ligand for $\alpha \mathrm{E} \beta 7$ is E-cadherin, which is expressed on epithelial cells. In this article, molecular aspects of ligand recognition by $\alpha \mathrm{E} \beta 7$ in relation to recent structural data on cadherin domains are reviewed. Expression of $\alpha \mathrm{E} \beta 7$ is often increased in inflammatory diseases, particularly where $T$ cells infiltrate epithelial tissues. The function of $\alpha \mathrm{E} \beta 7$ is not yet fully understood, but it is likely to be important in retention of $T$ cells in mucosal tissues and may also have a role in cell signalling and communication between lymphocytes and epithelial surfaces.
\end{abstract}

(F Clin Pathol: Mol Pathol 1999;52:203-207)

Keywords: $\alpha \mathrm{E} \beta 7$ integrin; cell signalling; $\mathrm{T}$ cells; inflammatory diseases

The integrin $\alpha \mathrm{E} \beta 7$ (CD103) is expressed mainly by cells of the $\mathrm{T}$ lymphocyte lineage within mucosal tissues. ${ }^{12}$ This is a strikingly narrow pattern of expression compared with that of other integrins. Lymphocytes expressing $\alpha \mathrm{E} \beta 7$ are abundant in the gut and comprise a major part of the total $\mathrm{T}$ cell complement of the body. The integrin is present on $\mathrm{T}$ cells within or closely juxtaposed to epithelia and it is expressed at very high levels on all intraepithelial lymphocytes (IELs) in gut villi and on about $50 \%$ of $\mathrm{T}$ cells in the lamina propria. It is also found on mucosal dendritic antigen presenting cells, bronchoalveolar lavage $\mathrm{T}$ cells, and activated mucosal mast cells. ${ }^{3-5}$ Expression is induced and maintained by transforming growth factor $\beta$ (TGF- $\beta$ ), ${ }^{6}$ and ligation of $\beta 1$ integrins has been reported to costimulate expression. ${ }^{4}$

Only two integrins use the $\beta 7$ subunit and each is particularly important in the mucosal immune system. The sister molecule to $\alpha \mathrm{E} \beta 7$, $\alpha 4 \beta 7$, is the homing receptor that directs lymphocytes to the gut mucosa and Peyer's patches. $^{7}$ Its principal ligand is the mucosal vascular addressin MAdCAM-1 (mucosal addressin cell adhesion molecule) on mucosal endothelial cells. In contrast, $\alpha \mathrm{E} \beta 7$ does not recognise MAdCAM-1 and neither does it have a role in lymphocyte homing. ${ }^{8}$ Expression of the $\alpha \mathrm{E}$ subunit is believed to be induced by TGF- $\beta$, produced mainly by epithelial cells, after $\mathrm{T}$ cells have migrated to mucosal tissues.

The gene for the human $\alpha \mathrm{E}$ subunit is on chromosome 17 and contains 31 exons spanning more than $75 \mathrm{~kb}$ (PJ Kilshaw, 1999, unpublished data). The 5' upstream proximal promoter contains numerous copies of the TGF- $\beta$ response element, ${ }^{9}$ which binds Smad transcription factors. Nevertheless, the proximal promoter alone does not determine $\mathrm{T}$ cell specificity and TGF- $\beta$ responsiveness. Experiments are in progress to identify additional enhancer elements elsewhere in the gene. The $\beta 7$ gene, which is far more widely transcribed in lymphoid tissues, ${ }^{10}$ has two functional TGF- $\beta$ response regions in the promoter. ${ }^{11}$ Transcription induced by TGF- $\beta$ depends on tyrosine phosphorylation of putative transcription factors that bind to these regions. ${ }^{11}$

\section{The ligand for $\alpha \mathrm{E} \beta 7$ is E-cadherin}

Experiments in the mouse and human established that the ligand for this integrin is expressed exclusively by epithelial cells and that it is E-cadherin. ${ }^{12-15}$ Thus, $\alpha \mathrm{E} \beta 7$ caused adhesion of mucosal $\mathrm{T}$ cells to cultured gut epithelial cells in vitro. ${ }^{12}{ }^{13}$ Importantly, spontaneous or lectin induced cytotoxic effector function of IELs against epithelial cell targets could be inhibited by blocking the integrincadherin interaction. ${ }^{13}{ }^{16}$ So far, no other ligand for $\alpha E \beta 7$ has been identified.

E-cadherin is a calcium dependent, homophilic cell adhesion molecule expressed by epithelial cells. It plays a vital role in embryonic development and in the polarisation of epithelial cells. ${ }^{17}{ }^{18}$ It is concentrated in adherens junctions between epithelial cells and is detectable also at the basolateral membrane. E-cadherin comprises five extracellular domains, each made up of $\sim 110$ amino acids arranged as seven $\beta$ sheets in an immunoglobulin (Ig) fold. ${ }^{19}$ Nine calcium atoms are bound in the interdomain junctions and these are important for maintaining the rod-like conformation and functional activity of the molecule. ${ }^{20}$ Adjacent E-cadherin molecules on the cell surface can dimerise in parallel, and this is thought to be a prerequisite for homophilic adhesive interactions between E-cadherin molecules on opposing cells. ${ }^{2122}$

\section{Structural requirements for recognition} of E-cadherin by $\alpha E \beta 7$

Extracellular domains 1 and 2 of E-cadherin are required for recognition by $\alpha \mathrm{E} \beta 7 .{ }^{23}$ Alanine point mutations of six acidic residues within domain 1 (fig 1) revealed an essential integrin recognition motif in a highly flexible quasi helix connecting $\beta$ strands $\mathrm{B}$ and $\mathrm{C}$. The mutation Glu 31/Ala in this loop prevented binding to
Accepted for publication 11 March 1999 


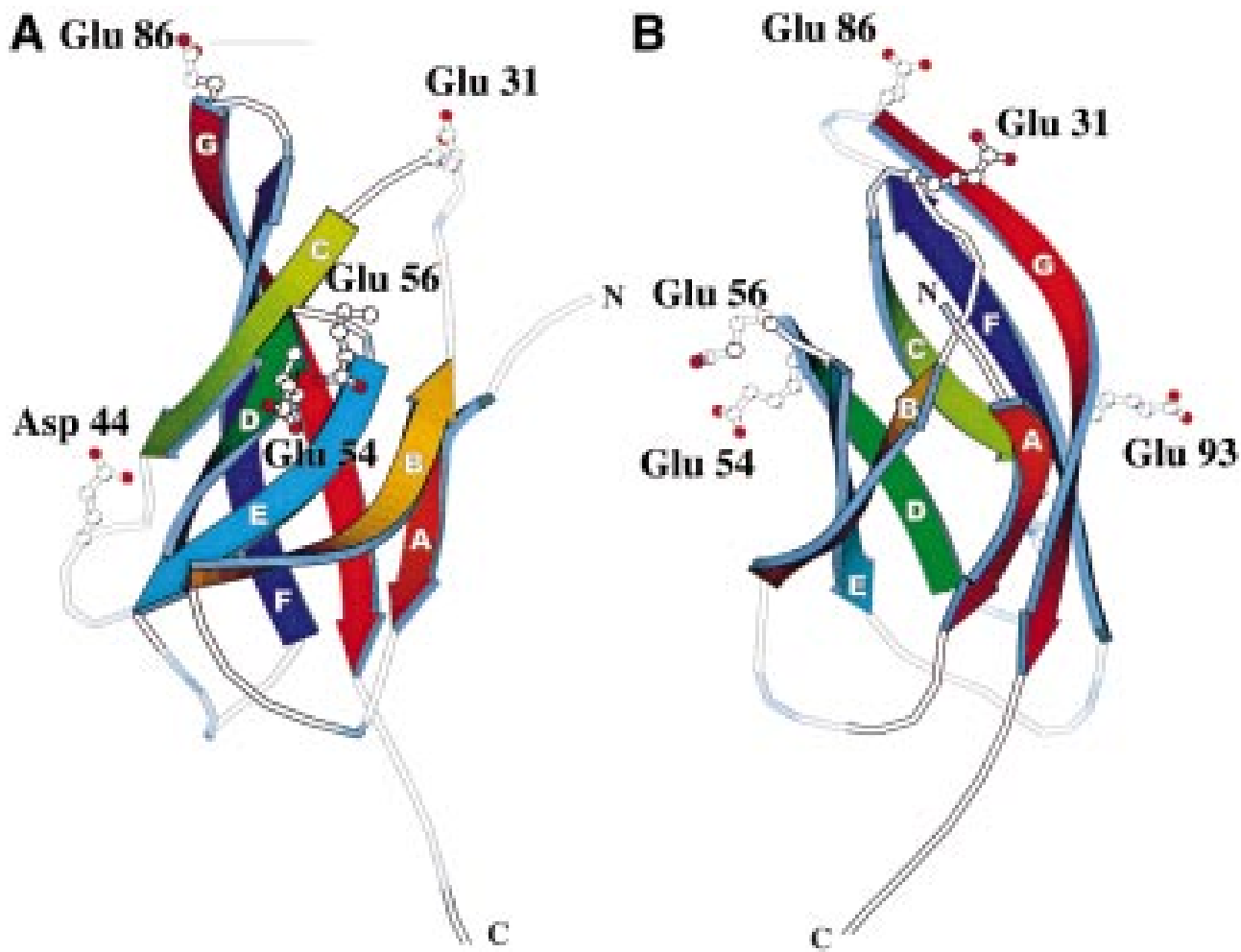

Figure 1 Model of E-cadherin domain 1 showing the positions of six acidic amino acids that were mutated to alanine; $(A)$ and $(B)$ differ by $90^{\circ}$ in the vertical axis. Only the mutation at Glu31 inhibited recognition by aE $\beta 7$.

$\alpha \mathrm{E} \beta 7 .^{23}$ The location of the integrin binding site in E-cadherin differs from that of other integrin ligands of the Ig superfamily, such as intercellular adhesion molecule 1 (ICAM-1), ICAM-2, ICAM-3, vascular cell adhesion molecule 1 (VCAM-1), and MAdCAM-1, in which the CD region on the CFG face of domain 1 is important for recognition by integrins. ${ }^{24}{ }^{25} \mathrm{In}$ E-cadherin, the BC loop is distant from both the CFG surface, which is required for homophilic adhesion, and the $\mathrm{AB}$ face, which is involved in strand dimerisation..$^{20} \mathrm{~A}$ cyclic peptide mimicking the BC loop failed to inhibit integrin binding, ${ }^{23}$ indicating that additional contact sites may be required. Other members of the cadherin family do not contain the $\mathrm{BC}$ recognition motif and show little or no adhesion to $\alpha \mathrm{E} \beta 7$. Human, but not mouse, $\mathrm{P}$-cadherin contains aspartic acid rather than glutamic acid in the crucial position of the BC loop and supports very weak adhesion to $\alpha \mathrm{E} \beta 7 .{ }^{26}$

Domain 2 of E-cadherin is essential for the engagement of $\alpha \mathrm{E} \beta 7$ but its precise role is not understood. This domain might provide additional contact sites for the integrin. Another possibility is that $\alpha \mathrm{E} \beta 7$ recognises $\mathrm{E}$-cadherin only as a strand dimer. In this case, domain 2 would be required for lateral dimerisation. ${ }^{21} 27{ }^{28}$ Dimerisation could provide the rigidity necessary for integrin binding; alternatively, two separate sites on the integrin could engage the two cadherin molecules. Two models for dimer formation have been proposed, based on $x$ ray crystallography. One directly involves calcium in the junction between domains 1 and $2,{ }^{21}$ the other requires the mutual intercalation of tryptophan residues in the first domains of adjacent cadherin molecules. ${ }^{20}$ Each model is supported by experimental evidence. Calcium is required for dimerisation of recombinant E-cadherin domains 1 and 2 in solution, ${ }^{27}$ but is not necessary for dimer formation on the cell surface ${ }^{29}$ or for adhesion between $\alpha \mathrm{E} \beta 7$ and the E-cadherin-Fc fusion protein. ${ }^{26}$ In either model, the integrin recognition motifs of the two E-cadherin molecules are in close apposition (fig 2), so it is enticing to speculate that both loops could be engaged simultaneously by one integrin molecule. The stoichiometry of the interaction has not yet been investigated. Regardless of whether or not dimerisation is necessary for binding to $\alpha \mathrm{E} \beta 7$, it is clear that the C-terminal region of the cytoplasmic domain that links E-cadherin to the cytoskeleton is not required for recognition by the integrin. ${ }^{23}$ The role of this region in regulating lateral dimerisation and clustering is complex and not yet fully resolved. ${ }^{3031}$

In common with six other integrin $\alpha$ subunits $(\alpha 1, \alpha 2, \alpha \mathrm{L} \alpha \mathrm{M} \alpha \mathrm{X}$, and $\alpha \mathrm{D}), \alpha \mathrm{E}$ contains an I domain. ${ }^{32}$ This structure forms a "Rossmann" fold incorporating a metal ion dependent adhesion site, which is thought to contribute a major part of the ligand binding activity of the integrin molecule. ${ }^{33}$ Recombinant I domains of $\alpha 1, \alpha 2, \alpha \mathrm{M}$, and $\alpha \mathrm{L}$ subunits exhibit divalent cation dependent ligand binding activity in isolation from the rest of the molecule. ${ }^{34-37}$ This has not yet been demonstrated for $\alpha \mathrm{E}$, but the I domain is clearly important for ligand recognition because an antibody that blocks $\alpha \mathrm{E} \beta 7$ function (M290) recognises an epitope in this region (PJ Kilshaw, 1999, unpublished data). 


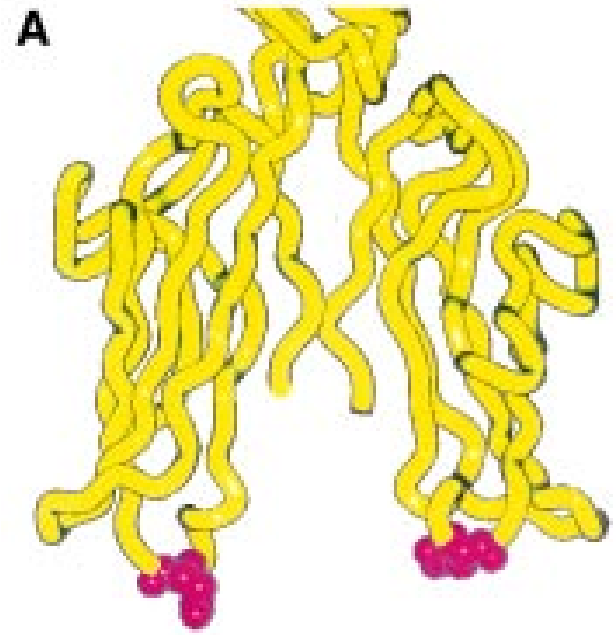

B

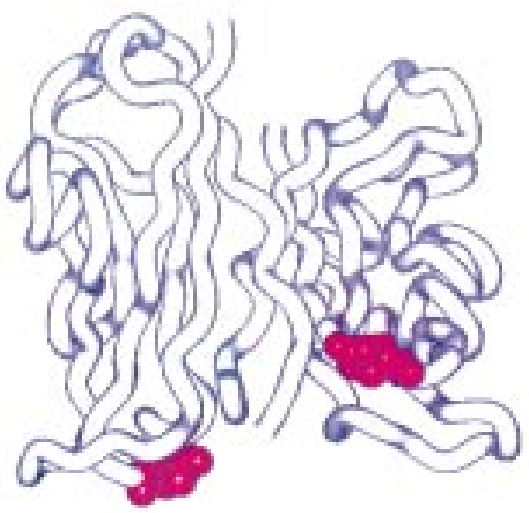

Figure 2 Two interpretations of E-cadherin domain 1 in dimeric form. (A) Calcium dependent dimer according to the model of Nagar et al. ${ }^{21}$ (B) Tryptophan dependent dimer based on the the model of Shapiro et al for $N$-cadherin. ${ }^{20}$ In each case Glu 31 is shown in magenta.

\section{$\alpha \mathrm{E} \beta 7$ in disease}

In Crohn's disease, the expression of $\alpha \mathrm{E} \beta 7$ on IELs in the ileum is reduced. This change is seen in both inflamed and non-inflamed regions, and might be an early sign of incipient disease. ${ }^{38}$ Conversely, in mouse models of colitis, such as that induced by injection of $\mathrm{CD}^{+}$ CD45RB ${ }^{\text {hi }}$ cells into severe combined immunodeficient (SCID) mice, the $\mathrm{T}$ cells that infiltrate the epithelium are $\alpha \mathrm{E} \beta 7$ positive. ${ }^{39}$ In Sjogren's syndrome, a T cell mediated autoimmune disease of salivary and lacrimal glands, the effector $\mathrm{CD}^{+} \mathrm{T}$ cells that are found in close association with the acinar and ductal epithelium express $\alpha \mathrm{E} \beta 7 .^{40}{ }^{41}$ Increased expression of $\alpha E \beta 7$ is also seen on cultured peripheral blood $\mathrm{T}$ cells in systemic lupus erythematosus with epithelial involvement, ${ }^{42}$ and in cutaneous $\mathrm{T}$ cell lymphomas. ${ }^{43}$ In normal lung, most $\mathrm{CD}^{+} \mathrm{T}$ cells and a few $\mathrm{CD} 4^{+}$cells in bronchoalveolar lavage fluid are $\alpha \mathrm{E} \beta 7$ positive. ${ }^{4}$ The expression of $\alpha \mathrm{E} \beta 7$, particularly on $\mathrm{CD} 4^{+}$cells, increases dramatically in certain types of pulmonary inflammation, such as sarcoidosis, hypersensitivity pneumonitis, and idiopathic pulmonary fibrosis. ${ }^{4}$ This integrin may also be relevant in allotransplantation because $\mathrm{CD}^{+}$ cytotoxic $\mathrm{T}$ lymphocytes (CTLs) found in close apposition to the tubular epithelium of renal allografts undergoing chronic rejection express $\alpha \mathrm{E} \beta 7$ (JA Kirby, 1999, unpublished data). Moreover, about $50 \%$ of the CTLs generated in vitro in response to allogeneic renal epithelial cells express $\alpha E \beta 7$, a feature that biases their effector function towards epithelial target cells as opposed to lymphocytic targets. ${ }^{44}$ $\alpha \mathrm{E} \beta 7$ has also been detected in the inflamed synovium and it is notable that its ligand, E-cadherin, is strongly expressed by synovocytes. ${ }^{45}$ It is sometimes assumed that $\alpha \mathrm{E} \beta 7^{+} \mathrm{T}$ cells that infiltrate non-mucosal organs are gut derived. In most instances a more plausible explanation is that integrin expression is induced in situ by the influence of TGF- $\beta$ in the local microenvironment.

So far, the importance of $\alpha \mathrm{E} \beta 7$ in animal models of inflammatory disease has been assessed in only one study. ${ }^{45 a}$ A blocking antibody, M290, to the $\alpha \mathrm{E}$ subunit was shown to prevent or ameliorate immunisation induced colitis in interleukin 2 deficient mice. The effect was attributed to reduced retention of $\mathrm{CD}^{+} \mathrm{T}$ cells in the mucosa. In addition to a role in tissue retention, $\alpha \mathrm{E} \beta 7$ might also contribute directly to $\mathrm{T}$ cell mediated damage of epithelial cells. In this case, inhibition of the interaction between $\alpha \mathrm{E} \beta 7$ and E-cadherin could be beneficial. This strategy would be especially appropriate in circumstances in which $\alpha \mathrm{E} \beta 7$ provides the dominant adhesion pathway between the $\mathrm{T}$ cell and its target-for example, when ICAM-1 is absent from the epithelium or is inaccessible or expressed at low levels, such as in inflamed gut. ${ }^{467}$

\section{The function of $\alpha E \beta 7$ : facts and speculations}

It has been widely assumed that $\alpha \mathrm{E} \beta 7$ serves to locate and retain $\mathrm{T}$ cells at epithelial surfaces by engaging E-cadherin on the basolateral surface of epithelial cells. Although the assumption may be correct, this adhesion pathway is not a prerequisite for penetration of lymphocytes into epithelia. $T$ cells that infiltrate the gut epithelium in graft versus host disease lack $\alpha \mathrm{E} \beta 7 .{ }^{1}$ Furthermore, IELs are abundant in regions of inflamed gut epithelium in which E-cadherin is lacking as a result of genetic manipulation. ${ }^{48}$ Ablation of $\alpha \mathrm{E} \beta 7$ function in vivo either with antibodies or by knockout technology has, so far, failed to give an adequate picture of its function in healthy or antigen challenged mice, although it is notable that IELs in the gut of $\alpha \mathrm{E}^{-/-}$mice are somewhat reduced in number (C M Parker, 1998, unpublished data). In common with other integrins, the adhesive function of $\alpha \mathrm{E} \beta 7$ is regulated by modulating affinity or avidity. ${ }^{49}$ Treatment of lymphocytes with phorbol ester or ligation of the $\mathrm{T}$ cell receptor complex increases the adhesive capacity of $\alpha \mathrm{E} \beta 7$ and the addition of manganese ions increases affinity. ${ }^{26}$ Recently, the cytoplasmic tails of both $\alpha \mathrm{E}$ and $\beta 7$ have been shown to associate with the WD repeat protein WAIT-1, which is thought to play a part in regulating adhesion, although the mechanism is not understood. ${ }^{50}$ The functional state of $\alpha \mathrm{E} \beta 7$ on IELs in the normal gut is unclear and it is possible that engagement of 
E-cadherin on the epithelial cell occurs only after the $T$ cell has been stimulated by antigen.

Both E-cadherin and $\alpha \mathrm{E} \beta 7$ take part in cell signalling. Crosslinking the integrin costimulates the proliferative response and cytotoxic function of IELs. ${ }^{131}$ E-cadherin, in addition to its role as a cell adhesion molecule, has profound effects on the morphological and genetic regulation of epithelial cells. Impaired function of E-cadherin resulting from point mutations or reduced expression is associated with dysplasia, genetic instability, and progression to neoplasia. ${ }^{52-54} \beta$-Catenin may provide the connection between adhesion and gene transcription. This protein links the cytoplasmic domain of E-cadherin to the cytoskeleton in adherens junctions. In this way, cell adhesion can influence the cytoplasmic pool of free, unassociated $\beta$-catenin. This pool is also regulated by the Wnt signalling pathway. ${ }^{55}$ Free $\beta$-catenin is transported to the nucleus, where it activates transcription factors that act upon genes involved in oncogenic progression. The engagement of E-cadherin by $\alpha \mathrm{E} \beta 7$ on $\mathrm{T}$ cells patrolling the epithelium would be expected to perturb E-cadherin homotypic adhesion and may affect the interaction of the cytoplasmic domain with $\beta$-catenin or other proteins associated with this signalling pathway. By this means, $\alpha \mathrm{E} \beta 7$ could influence gene transcription in epithelial cells.

The role of $\alpha \mathrm{E} \beta 7$ as an adhesion molecule is only partly understood. Its importance in disease and its potential role as a conduit for the transfer of information between lymphocytes, epithelial cells, and the external environment invites further exploration.

1 Kilshaw PJ, Baker KC. A unique surface antigen on intraepithelial lymphocytes in the mouse. Immunol Let 1988;18:149-54.

2 Cerf-Bensussan N, Jarry A, Brousse N, et al. A monoclonal antibody (HML-1) defining a novel membrane molecule present on human intestinal lymphocytes. Eur $\mathcal{F}$ Immunol present on human

3 Kilshaw PJ. Expression of the mucosal $\mathrm{T}$ cell integrin $\alpha_{\mathrm{M} 290} \beta 7$ by a major subpopulation of dendritic cells in mice. Eur $\mathcal{F}$ Immunol 1993;23:3365-8.

4 Rihs S, Walker C, Virchow JC, et al. Differential expression of $\alpha \mathrm{E} \beta 7$ integrins on bronchoalveolar lavage $\mathrm{T}$ lymphocyte subsets: regulation by $\alpha 4 \beta 1$ crosslinking and TGF-beta. Am $\mathcal{F}$ Respir Cell Mol Biol 1996;15:600-10.

5 Smith TJ, Ducharme LA, Shaw SK, et al. Murine M290 integrin expression modulated by mast cell activation. integrin expression modu

6 Kilshaw PJ, Murant SJ. A new surface antigen on intraepithelial lymphocytes in the intestine. Eur $\mathcal{F}$ Immunol 1990;20:2201-7.

7 Hamann A, Andrew DP, Jablonski-Westrich D, et al. Role of a4 integrins in lymphocyte homing to mucosal tissues in vivo. F Immunol 1994;152:3282-93.

8 Austrup F, Rebstock S, Kilshaw PJ, et al. Transforming growth factor beta 1-induced expression of the mucosa-
related integrin $\alpha \mathrm{E}$ on lymphocytes is not associated with mucosa-specific homing. Eur f Immunol 1995;25:1487-91.

9 Shi YG, Wang YF, Jayaraman L, et al. Crystal structure of a Smad MH1 domain bound to DNA: insights on DNA binding in TGF- $\beta$ signaling. Cell 1998;94:585-94.

10 Kilshaw PJ, Murant S. Expression and regulation of $\beta 7(\beta \mathrm{p})$ integrins on mouse lymphocytes: relevance to the mucosal mmune system. Eur F Immunol 1991;21:2591-7.

$11 \mathrm{Lim}$ PS, Leung E, Krissansen GW. The $\beta 7$ integrin gene (Itgb-7) promoter is responsive to TGF- $\beta 1$. Immunogenetics 1998;48:184-95.

12 Cepek KL, Parker, CM, Madara JL, et al. Integrin $\alpha \mathrm{E} \beta 7$ mediates adhesion of T lymphocytes to epithelial cells. $f$ Immunol 1993;150:3459-70.

13 Roberts K, Kilshaw PJ. The mucosal $\mathrm{T}$ cell integrin $\alpha M 290 \beta 7$ recognises a ligand on mucosal epithelial cell lines. Eur f Immunol 1993;23:1630-5.

14 Cepek KL, Shaw SK, Parker CM, et al. Adhesion between epithelial cells and T lymphocytes mediated by E-cadherin and the $\alpha \mathrm{E} \beta 7$ integrin. Nature 1994;372:190-3.
15 Karecla PI, Bowden SJ, Green SJ, et al. Recognition of E-cadherin on epithelial cells by the mucosal T cell integrin $\alpha \mathrm{M} 290 \beta 7$ ( $\alpha \mathrm{E} \beta 7)$. Eur f Immunol 1995;25:852-6.

16 Roberts AI, O'Connell SM, Biancone L, et al. Spontaneous cytotoxicity of intestinal intraepithelial lymphocytes: clues to the mechanism. Clin Exp Immunol 1993;94:527-32.

17 Marrs JA, Nelson WJ. Cadherin cell adhesion molecules in differentiation and embryogenesis. Int Rev Cytol 1996;165: 159-205.

18 Yap AS, Brieher WM, Gumbiner BM. Molecular and functional analysis of cadherin-based act

19 Overduin M, Harvey TS, Bagby S, et al. Solution structure of the epithelial cadherin domain responsible for selective of the epithelial cadherin domain respon. Science 1995;267:386-9.

20 Shapiro L, Fannon AM, Kwong PD, et al. Structural basis of cell-cell adhesion by cadherins. Nature 1995;374:327-37.

21 Nagar B, Overduin M, Ikura M, et al. Structural basis of calcium-induced rigidification and dimerization. Nature 1996;380:360-4.

22 Tomschy A, Fauser, C, Landwehr R, et al. Homophilic adhesion of E-cadherin occurs by a co-operative two-step interaction of N-terminal domains. EMBO f 1996;15: 3507-14.

23 Karecla PI, Green SJ, Bowden SJ, et al. Identification of a binding site for integrin $\alpha \mathrm{E} \beta 7$ in the N-terminal domain of E-cadherin. F Biol Chem 1996;271:30909-15.

24 Holness CL, Simmons DL. Structural motifs for recognition and adhesion in members of the immunoglobulin superfamily. 7 Cell Sci 1994;107:2065-70.

25 Viney JL, Jones S, Chiu HH, et al. Mucosal addressin cell adhesion molecule-1: a structural and functional analysis demarcates the integrin binding motif. F Immunol 1996; 157:2488-97. $26 \begin{aligned} & \text { Higgins JMG, Mandlebrot DA, Shaw SK, et al. Direct and } \\ & \text { regulated interaction of integrin } \alpha \mathrm{E} \beta 7 \text { with E-cadherin. } \mathcal{F}\end{aligned}$ Cell Biol 1998;140:197-210.

27 Alattia JR, Ames JB, Porumb T, et al. Lateral self-assembly of E-cadherin directed by co-operative calcium binding. FEBS Lett 1997;417:405-8.

28 Koch AW, Pokutta S, Lustig A, et al. Calcium binding and homoassociation of E-cadherin domains. Biochemistry 1997;36:7697-705.

29 Chitaev NA, Troyanovsky SM. Adhesive but not lateral E-cadherin complexes require calcium and catenins for heir formation. F Cell Biol 1998;142:837-46.

30 Yap AS, Niessen CM, Gumbiner BM. The juxtamembrane region of the cadherin cytoplasmic tail supports lateral clustering, adhesive strengthening and interaction with p129 (ctn). F Cell Biol 1998:141:779-89.

31 Ozawa M, Kemler R. The membrane-proximal region of the E-cadherin cytoplasmic domain prevents dimerization and negatively regulates adhesion activity. f Cell Biol 1998;142: 1605-13.

32 Shaw SK, Cepek KL, Murphy EA, et al. Molecular cloning of the human mucosal lymphocyte integrin $\alpha \mathrm{E}$ subunit. $\mathscr{f}$ Biol Chem 1994;269:6016-25.

33 Dickeson SK, Santoro SA. Ligand recognition by the I domain-containing integrins. Cell Mol Life Sci 1998;54: 556-66.

34 Randi AM, Hogg N. I domain of beta 2 integrin lymphocyte function-associated antigen-1 contains a binding site for igand intracellular adhesion molecule-1. F Biol Chem 1994;269:12395-8.

35 Ueda T, Rieu P, Brayer J, et al. Identification of the compleCD11b/CD18) Proc Natl Acad Sci USA 1994;91:106804.

36 Kamata T, Takada Y. Direct binding of collagen to the I-domain of integrin alpha-2 beta-1 (VLA-2, CD49b/ CD29) in a divalent cation-dependent manner. F Biol Chem 1994;269:26006-10.

37 Calderwood DA, Tuckwell DS, Eble J, et al. The integrin $\alpha 1$ A-domain is a ligand binding site for collagens and laminin. F Biol Chem 1997;272:12311-17.

38 Elewaut D, Van Damme N, De Keyser F, et al. Altered expression of alpha $\mathrm{E}$ beta 7 integrin on intraepithelial and lamina propria lymphocytes in patients with Crohn's disease. Acta Gastroenterol Belg 1998;61:288-94.

39 Aranda R, Sydora BC, McAllister PL, et al. Analysis of intestinal lymphocytes in mouse colitis mediated by transfer of $\mathrm{CD}^{+}, \mathrm{CD} 45 \mathrm{RBhigh} \mathrm{T}$ cells to SCID recipients. $\mathcal{F}$ Immunol 1997;158:3464-73.

40 Kroneld U, Jonsson R, Carlsten H, et al. Expression of the mucosal lymphocyte integrin $\alpha \mathrm{E} \beta 7$ and its ligand E-cadherin in salivary glands of patients with Sjogren's E-cadherin in salivary glands of patients with
syndrome. Scand $\mathcal{F}$ Rheumatol 1998;27:215-18.

41 Fujihara $T$, Fujita $H$, Tsubota $K$, et al. Lacrimal gland is destroyed by $\mathrm{CD}^{+} \mathrm{CD} 103^{+} \mathrm{T}$ lymphocytes in patients with Sjogren's syndrome [abstract]. Invest Ophthalmol Vis Sci 1997;38:2044

42 Pang M, Abe T, Fujihara T, et al. Up-regulation of alpha E beta 7 , a novel integrin adhesion molecule, on $\mathrm{T}$ cells from systemic lupus erythematosus patients with specific epithelial involvement. Arthritis Rheum 1998;41:1456-63.

43 Dietz SB, Whitaker-Menezes D, Lessin SR. The role of alpha $\mathrm{E}$ beta 7 integrin (CD103) and E-cadherin in epidermotropism in cutaneous T-cell lymphoma. f Cutan Pathol 1996;23:312-18.

44 Hadley GA, Bartlett ST, Via CS, et al. The epithelial cell-specific integrin, CD103 ( $\alpha \mathrm{E}$ integrin) defines a novel subset of alloreactive CD8 ${ }^{+}$CTL. F Immunol 1997;159. 3748-56. 
45 Trollmo C, Nilsson IM, Sollerman C, et al. Expression of the mucosal lymphocyte integrin alpha $\mathrm{E}$ beta 7 and its ligand E-cadherin in the synovium of patients with rheumatoid arthritis. Scand F Immunol 1996;44:293-8.

45a Lúdviksson BR, Strober W, Nishikomori R, et al. Administration of $\mathrm{mAb}$ against $\alpha \mathrm{E} \beta 7$ prevents and ameliorates immunization-induced colitis in $\mathrm{IL}-2^{-/-}$mice. $f$ Immuno 1999;162:4975-82

46 Bloom S, Simmons D, Jewell DP. Adhesion molecules intercellular adhesion molecule-1 (ICAM-1), ICAM-3 and B are not expressed by epithelium in normal or inflamed colon. Clin Exp Immunol 1995;101:157-63.

47 Parkos CA, Colgan SP, Diamond MS, et al. Expression and polarization of intercellular adhesion molecule-1 on human intestinal epithelia: consequences for CD11b/CD18mediated interactions with neutrophils. Mol Med 1996;2: 489-505.

48 Hermiston ML, Gordon JI. Inflammatory bowel disease and adenomas in mice expressing a dominant negative N-cadherin. Science 1995;270:1203-7.

49 Stewart M, Hogg N. Regulation of leukocyte integrin function: affinity vs. avidity. $\mathcal{F}$ Cell Biochem 1996;61:554 61.
50 Rietzler M, Bittner M, Kolanus W, et al. The human WD repeat protein WAIT-1 specifically interacts with the cytoplasmic tails of $\beta 7$-integrins. F Biol Chem 1998;42: 27459-66.

51 Sarnacki S, Begue B, Buc H, et al. Enhancement of CD3-induced activation of human intestinal intraepithelial ymphocytes by stimulation of the $\beta 7$ integrin defined by HML-1 monoclonal antibody. Eur f Immunol 1992;22: 2887-92.

52 Jankowski JA, Bedford FK, Boulton RA, et al. Alterations in classical cadherins associated with progression in ulcerative and Crohn's colitis. Lab Invest 1998;78:1155-67.

53 Tlsty TD. Cell adhesion-dependent influences on genomic instability and carcinogenesis. Curr Opin Cell Biol 1998;10: 647-53.

54 Hermiston ML, Gordon JI. In vivo analysis of cadherin function in the mouse intestinal epithelium: essential roles in adhesion, maintenance of differentiation and regulation of programmed cell death. F Cell Biol 1995;129:489-506.

55 Ben-Ze'ev A, Geiger B. Differential molecular interaction of $\beta$-catenin and plakoglobin in adhesion, signaling and cancer. Curr Opin Cell Biol 1998;10:629-39. 